\title{
Angiotensin-converting enzyme inhibitors as a cause of isolated angioedema in a Slovenian population
}

\author{
Cita Zupanc ${ }^{1,2}$, Mitja Košnik ${ }^{1,2 \bowtie}$
}

\begin{abstract}
Introduction: Angioedema (AE) is a localized swelling of the subcutaneous tissue and mucosa. We aimed to identify how often AE is associated with angiotensin-converting enzyme inhibitor (ACEI-AE) therapy and whether the severity of AE episodes in these patients differs from the severity in idiopathic AE (IAE).

Methods: We included patients with AE that were referred to a tertiary allergy clinic from 2005 to 2014. We obtained data on AE location, severity, number, and treatment of episodes from patient medical files. Patients treated with ACEl were contacted to obtain follow-up data on the effect of ACEI discontinuation.

Results: A total of 603 patients with AE were referred (59.9\% women) to our clinic. A total of $36.9 \%$ had AE associated with urticaria or anaphylaxis. Among 381 patients with isolated $A E, 10.5 \%$ of the patients were diagnosed with identified causes. The proportion of ACEI-AE was $27.1 \%$ to $37.9 \%(95 \% \mathrm{CI})$; others were classified as IAE. ACEI-AE cases had more severe episodes compared to IAE cases, which were more likely to be treated by a family doctor or even hospitalized.

Conclusion: ACEl was shown to be the most frequent removable cause of isolated AE. About two-thirds of AE cases taking ACEl were resolved after removal of the drug.
\end{abstract}

Keywords: angioedema, ACE inhibitors, epidemiology

Received: 24 October 2015 | Returned for modification: 30 November 2015 | Accepted: 24 December 2015

\section{Introduction}

Angioedema (AE) is a localized swelling of the subcutaneous tissue and/or submucosa. A sudden local increase in the permeability of capillaries and post-capillary venules causes a fluid shift from plasma to interstitium. A number of mediators can increase microvascular permeability; for example, histamine, arachidonic acid metabolites (prostaglandins, leukotrienes), and bradykinin. Based on the physiological mechanism, AE is divided into two major groups: mastocyte-mediator-induced AE (histaminergic $\mathrm{AE})$ and bradykinin-induced AE (1).

Episodes of swelling develop in minutes to hours (1). The skin over the AE may be erythematous or have a normal skin color. AE may be painful. Pruritus is rarely present (2). When AE is not accompanied by urticaria it is called isolated AE (3). AE most frequently involves the tongue, lips, face, and, less frequently, the extremities, genitalia, or intestines (4). When AE involves the tongue or larynx, it is a life-threatening condition due to the risk of suffocation (5). In many patients, the etiology of AE is remains unknown and a diagnosis of idiopathic AE (IAE) is made (4).

In this report, we present data on the frequency of the causes and severity of isolated $\mathrm{AE}$ in patients attending a tertiary clinic. We aimed to identify how often AE is associated with angiotensinconverting enzyme inhibitor (ACEI-AE) therapy and whether the severity of $\mathrm{AE}$ episodes in these patients differs from the severity of idiopathic AE.

\section{Patients and methods}

\section{Patients}

We included patients with $\mathrm{AE}$ that were referred to a tertiary al- lergy clinic from 2005 to 2014. Using the hospital information system, we identified patients with a diagnosis of $\mathrm{T} 78.3$ according to ICD-10 (angioneurotic edema). We thoroughly examined patient medical records using a data-collection form for data on concomitant urticaria, other diagnoses that could explain edema, locations of angioedema, treatment of episodes (location and medicines used), atopy, and concomitant medications. We grouped patients as shown in Figure 1. First, we excluded patients that had AE in the course of urticaria or anaphylaxis. Then we separated patients with isolated AE due to identified causes (i.e., hereditary $\mathrm{AE}$, allergy, autoimmune diseases, histamine intolerance, $\mathrm{AE}$ of the uvula in patients with gastroesophageal reflux, and labial edema due to viral infections). Patients with no identified cause that were not receiving ACEI were regarded as IAE. We contacted patients that were receiving ACEI at the time of AE presentation by mail, explained the aim of the study, and asked them for permission to participate in a structured phone interview to obtain follow-up data on the effect of ACEI discontinuation. If AE did not occur 3 or more months after ACEI discontinuation, the patient was classified as ACEI-AE. Patients that did not respond to our invitation and those whose telephone numbers and e-mail addresses were not available were excluded from some parts of the analysis (comparison of characteristics of ACEI-induced AE vs. IAE).

\section{AE characteristics}

We obtained the data on AE location from patient medical files. AE severity was graded as mild (discomfort with no effect on daily activities), moderate (discomfort with an effect on daily activities), and severe (unable to perform daily activities or regular work). Treatment of the most severe episode anytime in the patient's 
history was graded as: 1 = did not seek medical attention at the time of AE symptoms; 2 = sought medical attention from the family physician or emergency department; and $3=$ hospitalization. The number of AE episodes in life was graded as 1 (1 or 2 AE episodes), 2 (3 to $10 \mathrm{AE}$ episodes), and 3 (more than 10 episodes).

\section{Statistical methods}

Data are presented as the mean and standard deviation. The statistical significance in the frequency of location of IAE and ACEI$\mathrm{AE}$ and associated signs and symptoms among the groups of patients were analyzed with Fisher's exact test.

Confidence intervals (CIs) were calculated as exact CIs for sample proportions. We took a more conservative approach (a wider CI) and calculated it only for patients that had a well-characterized origin of angioedema.

\section{Ethical approval}

The study was approved by the national ethics committee on February 18 th, 2014.

\section{Results}

\section{Proportion of types of AE}

In the 10-year period from 2005 to 2014,603 patients with $\mathrm{AE}$ were referred (59.9\% women) to our clinic. Among them, 36.9\% of $\mathrm{AE}$ was associated with urticaria or anaphylaxis, and $10.5 \%$ of patients were diagnosed with other identified causes (Fig. 1). Of the remaining, 170 were receiving ACEI, 134 were not receiving ACEI, and for 37 patients there were no data on ACEI in the medical file. Finally, 8o patients were diagnosed as ACEI-AE and 177 with IAE. For 84 patients, we did not have follow-up data (47 of these were treated with ACEI, and for 37 there were no data on ACEI treatment).

To estimate the proportion of ACEI-AE in the cohort of isolated $\mathrm{AE}$, we further analyzed 304 patients with a known ACEI treatment status. We first assessed a sample of ACEI-AE cases among patients with well-characterized origin of $\mathrm{AE}$ among patients taking ACEI. The proportion of ACEI-AE among these was 80/125 $(64 \%$; $95 \% \mathrm{CI}=54.9 \%-72.4 \%)$. We then extrapolated this num- ber to a sample of patients that were taking ACE inhibitors but in which we could not characterize the origin of AE, thus obtaining an additional 30 patients that were probably suffering from ACEI$\mathrm{AE}$ in the entire group of patients. This allowed us to evaluate the proportion of ACEI-AE in the entire sample (110/304 [36.2\%]). The $95 \%$ CI was $30.3 \%$ to $42.4 \%$.

\section{Characteristics of ACEI-AE and IA}

There was a significant difference between IA and ACEI-AE in the age and sex distributions (Table 1). IA was more common in women than in men, and ACEI-AE was equally distributed between sexes. The presence of atopy was not significantly different between the groups (IA $37.9 \%$ and ACEI-AE 26.2\%). The location of AE did not significantly differ between IA and ACEI-AE, although there was a tendency for a higher risk of oral cavity AE in ACEI-AE (Table 2). Significantly more patients with ACEI-AE complained of dyspnea (32 of $80 ; 40.0 \%$ ) compared to IA (39 of $177 ; 22.0 \% ; p$ $<$ o.01). The number, severity, and treatment of AE episodes are shown in Table 3. The number of episodes until referral to the clinic was not significantly different between IA and ACEI-AE; however, patients with ACEI-AE had more severe episodes compared to IA, and those episodes were more likely to be treated by a family doctor or patients were even hospitalized.

Table 1 | Age and sex distribution of IAE and ACEI-AE.

\begin{tabular}{lccc}
\hline & $\begin{array}{c}\text { Age (years) } \\
\text { Average } \pm \text { SD }\end{array}$ & \multicolumn{2}{c}{$\begin{array}{c}\text { Sex } \\
n(\%)\end{array}$} \\
\hline & & Male & Female \\
\cline { 2 - 4 } IAE $(\mathrm{n}=177)$ & $49.6 \pm 17.3$ & $62(35.0)$ & $115(65.0)$ \\
ACEI-AE $(\mathrm{n}=80)$ & $62.9 \pm 12.9$ & $43(53.8)$ & $37(46.2)$ \\
\hline & $p<0.01$ & \multicolumn{2}{c}{$p<0.01$} \\
\hline
\end{tabular}

Legend: $\mathrm{IAE}=$ idiopathic angioedema; $\mathrm{ACEI}-\mathrm{AE}=$ angiotensin-converting enzyme inhibitor-induced angioedema

Table 2 | Comparison of IAE and ACEI associated AE location.

\begin{tabular}{|c|c|c|c|c|}
\hline & \multicolumn{2}{|c|}{$\begin{array}{c}\text { Oral cavity } \\
\text { (tongue, pharynx, larynx) }\end{array}$} & \multicolumn{2}{|c|}{$\begin{array}{c}\text { Others areas } \\
\text { (lips, eyes, extremities) }\end{array}$} \\
\hline & Yes & $\mathrm{No} / \mathrm{NI}$ & Yes & $\mathrm{No} / \mathrm{NI}$ \\
\hline $\operatorname{IAE}(\mathrm{n}=177)$ & $80(45.2 \%)$ & $97(54.8 \%)$ & $149(84.18 \%)$ & $28(15.82 \%)$ \\
\hline ACEI-AE $(n=80)$ & $49(61.25 \%)$ & $31(38.75 \%)$ & $65(81.25 \%)$ & $15(18.75 \%)$ \\
\hline$p$ & \multicolumn{2}{|c|}{ NS } & \multicolumn{2}{|r|}{ NS } \\
\hline
\end{tabular}

Legend: $\mathrm{IA}=$ idiopathic angioedema; $\mathrm{ACEI}-\mathrm{AE}$ = angiotensin-converting enzyme inhibitor-induced angioedema; $\mathrm{NI}=$ no information. We assumed that, when the location of angioedema in a particular location was not mentioned in the patient's medical file, that location was not involved; NS = not significant

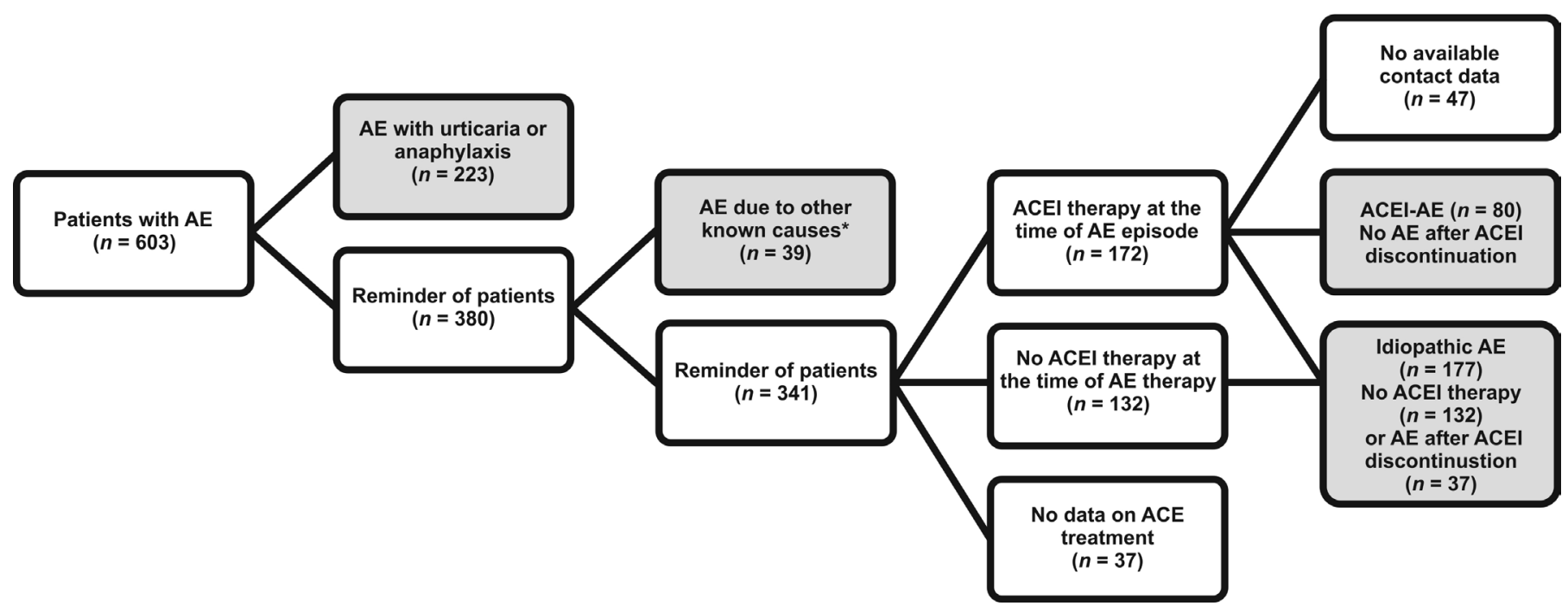

Figure 1 | Algorithm of patient gathering. Gray boxes represent final groups of patients.

*Out of 39 patients, 18 had hereditary AE, two had histamine intolerance, three had sartane hypersensitivity, three had autoimmune diseases, eight had gastroesophageal reflux-induced edema of the uvula, and five had lip edema due to local viral infection. 
Table 3 | Comparison of the number of AE episodes anytime in the past, episode severity (the most severe episode of each patient), and medical treatment of the most severe episodes between the IAE group and ACEI-AE.

\begin{tabular}{|c|c|c|c|c|c|c|c|c|c|}
\hline & \multicolumn{3}{|c|}{ Number of AE episodes anytime in the past } & \multicolumn{3}{|c|}{ Episode severity } & \multicolumn{3}{|c|}{ Medical treatment of the most severe episode } \\
\hline & $1-2$ & $3-10$ & $>10$ & Mild & Moderate & Severe & None & Family doctor & Hospitalization \\
\hline $\operatorname{IAE}(n=177)$ & 48 & 62 & 67 & 57 & 77 & 43 & 64 & 83 & 30 \\
\hline ACEI-AE $(n=80)$ & 30 & 26 & 24 & 14 & 36 & 30 & 14 & 45 & 21 \\
\hline$p$ & & NS & & & $p<0.001$ & & & $p<0.0015$ & \\
\hline
\end{tabular}

Legend: IAE = idiopathic angioedema; $\mathrm{ACEI}-\mathrm{AE}=$ angiotensin-converting enzyme inhibitor-induced angioedema; $\mathrm{NS}=$ not significant

Data were obtained from medical files

\section{Discussion}

We found that between $27.1 \%$ and $37.9 \%$ of the isolated $\mathrm{AE}$ cases in everyday clinical practice at the tertiary allergy clinic were due to ACEI, and $54.9 \%$ to $72.4 \%$ of $\mathrm{AE}$ in patients that were treated with ACEI had ACEI-AE. In spite of an extensive diagnostic workup and growing knowledge about the pathophysiology of AE, other specific causes of $\mathrm{AE}$ are rarely identified, and more than half of isolated AE remains idiopathic (6).

Atopy does not seem to be an important factor in the pathogenesis of isolated AE, as shown in our study. The sex distribution, age, frequency of signs, symptoms, and locations of AE found in our study were similar to reports in the literature $(4,6)$. In a study by Zingale et al., the face was involved in $81 \%$ of patients, the tongue and oral cavity in $45 \%$, other cutaneous sites in $17 \%$, upper airways in $20 \%$, and the bowel in $3 \%$ of patients.

Angiotensin-converting enzyme (ACE) catalyzes conversion of angiotensin I to angiotensin II, which is a potent vasoconstrictor. Inhibition of ACE with ACEI decreases the production of angiotensin II and thus lowers blood pressure. However, ACE is the main enzyme that is also responsible for the degradation of bradykinin. Although bradykinin is degraded by other peptidases-for example, aminopeptidases $\mathrm{M}$, carboxypeptidases $\mathrm{N}$, neutral endopeptidases, dipeptidyl peptidase IV, enkephalinases, or neprilysin-these enzymes are less effective than ACE (7). In susceptible individuals taking ACEI, alternative pathways for bradykinin degradation are less active, which in turn causes episodic accumulation of bradykinin and subsequently cough or AE (8). Risk of AE is increased in patients with certain polymorphisms. The insertion II genotype of insertion/deletion (I/D) ACE polymorphism is associated with low circulating ACE levels (9). Patients with C-2399A polymorphism have reduced activity of aminopeptidase $\mathrm{P}$ and a higher incidence of ACEI-AE. Because the gene is X-linked, it explains a higher frequency of ACEI-AE in women, as found in some studies. The bradykinin receptor B2R-9 allele has higher affinity for bradykinin and was associated with more severe episodes in cases of hereditary AE due to $\mathrm{C} 1 \mathrm{NH}$ deficiency (9). Substance P, which is also degraded by ACE, and additionally by neutral endopeptidases, can contribute to $\mathrm{AE}$ by increasing vascular permeability (10).

Up to $5 \%$ of patients do not tolerate ACEI, primarily due to cough, and AE occurs in $0.1 \%$ to $0.7 \%$ of patients taking ACEI (11). In a meta-analysis of 40 randomized controlled trials with 74,857 patients, AE occurred in $0.3 \%$ of patients receiving ACEI and in $0.11 \%$ of patients receiving angiotensin receptor blockers or placebo (12).

ACEI is a frequently used medication for hypertension, chronic heart failure, ischemic heart disease, diabetic nephropathy, and progressive renal failure. In the last few years, use of ACEI has increased substantially (13). In Slovenia, between 2003 and 2013, ACEI use has increased by $47.6 \%$ (14). Parallel with increased ACEI prescription, increased frequency of AE has also been no- ticed $(15,16)$. Holm and Ovesen showed a three-fold increase in ACE use from 2000 to 2009, and a 69\% higher incidence in ACEIAE in 2005-2009 compared to 2000-2004 (13).

AE usually manifests soon after initiating ACEI therapy, but can also manifest only after years of therapy (4). Our patients were diagnosed with ACEI-AE after a median of three to 10 episodes. IAE is more frequent in women than in men, as also shown in our study (4). However, in ACEI-AE, we found no difference in the sex distribution, as was also the case in the study of patients hospitalized for ACEI-AE (17). Patients with ACEI-AE are significantly older than patients with IAE, which can be explained by the fact that an ACEI is prescribed in advanced age.

ACEI-AE is more severe than IA, as also shown in our study. ACEI-AE is a potentially life-threatening condition $(17,18)$. In the United States, mortality due to AE increased in the last 30 years from 0.24 to 0.34 per million in spite of decreasing mortality due to hereditary AE (19). It is likely that the prevalence of life-threatening episodes is much higher than reported. In a 1-year period, we recognized two severe episodes with a need for intubation in a single Slovenian regional hospital (20). The frequency and severity of ACEI-AE was higher in African-Americans (21). It is believed that the tendency is genetically determined and related to polymorphic variants in genes that modulate the activity of aminopeptidases (22).

In our study, one-third of AE patients had ACEI therapy at presentation. Among these AE patients, approximately two-thirds no longer had AE episodes after ACEI discontinuation, but in the rest AE episodes continued, which means that ACEI therapy was not the main reason for AE but was only an aggravating factor.

No specific drugs are licensed for the treatment of ACEI-AE. The majority of patients are treated with antihistamines and systemic steroids. Epinephrine is not very effective in ACEI-AE. Some recent studies showed a much higher efficacy of icatibant. Icatibant is currently licensed only for treatment of patients with hereditary AE (23-25). Omalizumab was also shown to be effective in refractory IA (26).

There are some weaknesses in our study. It was predominantly retrospective and a single-center study. Only patients that had data on ACEI therapy in their medical chart and with a confirmed diagnosis were contacted. We were not able to contact all patients with a history of ACEI treatment. This approach might underestimate the number of patients with identified causes of AE (apart from ACEI).

In conclusion, ACEI treatment was shown to be the most frequent removable cause of isolated AE. About two-thirds of AE cases in patients taking ACEI are resolved after removal of the drug.

\section{Acknowledgement}

We thank Eva Cafuta for help with data collection and Julij Selb for statistical analysis. The authors declare no competing interests. 


\section{References}

1. Bas M, Adams V, Suvorava T, Niehues T, Hoffmann TK, Kojda G. Nonallergic angioedema: role of bradykinin. Allergy. 2007;62:842-56.

2. Kaplan AP, Greaves MW. Angioedema. J Am Acad Dermatol. 2005;53:373-88

3. Bernstein JA, Lang DM, Khan DA, Craig T, Dreyfus D, Hsieh F, et al. The diagnosis and management of acute and chronic urticaria: 2014 update. J Allergy Clin Immunol. 2014;133:1270-7.

4. Zingale LC, Beltrami L, Zanichelli A, Maggioni L, Pappalardo E, Cicardi B, et al. Angioedema without urticaria: a large clinical survey. CMAJ. 2006;175:1065-70.

5. Kim SJ, Brooks JC, Sheikh J, Kaplan MS, Goldberg BJ. Angioedema deaths in the United States, 1979-2010. Ann Allergy Asthma Immunol. 2014;113:630-4.

6. Levy J, Rivard GE, Wagner E, Beezhold D, Berlin N, Fan L, et al. Examination of genetic variants involved in generation and biodisposition of kinins in patients with angioedema. Allergy Asthma Clin Immunol. 2014;10:60.

7. Campo P, Fernandez TD, Canto G, Mayorga C. Angioedema induced by angiotensinconverting enzyme inhibitors. Curr Opin Allergy Clin Immunol. 2013;13:337-44.

8. Brugts JJ, Arima H, Remme W, Bertrand M, Ferrari R, Fox K, et al. The incidence and clinical predictors of ACE-inhibitor induced dry cough by perindopril in 27,492 patients with vascular disease. Int J Cardiol. 2014;20:718-23.

9. Hoover T1, Lippmann M, Grouzmann E, Marceau F, Herscu P. Angiotensin converting enzyme inhibitor induced angio-oedema: a review of the pathophysiology and risk factors. Clin Exp Allergy. 2010;40:50-61.

10. Kostis JB, Packer M, Black HR, Schmieder R, Henry D, Levy E. Omapatrilat and enalapril in patients with hypertension: the Omapatrilat Cardiovascular Treatment vs Enalapril (OCTAVE) trial. Am J Hypertens. 2004;17:103-11.

11. Sabroe RA, Black AK. Angiotensin-converting enzyme (ACE) inhibitors and angio-oedema. Br J Dermatol. 1997;136:153-8.

12. Makani H, Messerli FH, Romero J, Wever-Pinzon O, Korniyenko A, Berrios RS, et al. Meta-analysis of randomized trials of angioedema as an adverse event of reninangiotensin system inhibitors. Am J Cardiol. 2012;110:383-91.

13. Holm JP, Ovesen T. Increasing rate of angiotensin-converting enzyme inhibitorrelated upper airway angio-oedema. Dan Med J. 2012;59:A4449.

14. Podatki o porabi zdravil [Data on therapeutic drug use] [Internet]. Zavod za zdravstveno zavarovanje Slovenija. [cited 2015 Oct 15]. Available from: https://partner.zzzs.si/wps/portal/portali/aizv/zdravila_in_zivila_za_ posebne_zdravstvene_namene/podatki_o_porabi_zdravil/!ut/p/b1/o4 Sj9CPykssyoxPLMnMzovMAfGjzOJNDFo93Y39DTwt3MJcDDyDnD183by9jAoCDYEKIoEKzAx8HTo8DQw9LEy8HAo8TC18TM1NLYoMDAwJ6ffSjorPyU8CWhWuH4VfsRFUAT7LwAoMcABHA30_j_zcVP2 $\mathrm{C}_{3} \mathrm{lijKE}_{4} \mathrm{dRwBzob}{ }_{4} \mathrm{C} / \mathrm{dl}_{4} /$ d5/L2dJQSEvUUt3QS80SmtFL102XzQxRUIHMo8wSTg4UzEwQTJCNzZMToU. wODQw/. Slovene.
15. Roberts JR, Lee JJ, Marthers DA. Angiotensin-converting enzyme (ACE) inhibitor angioedema: the silent epidemic. Am J Cardiol. 2012;109:774-5.

16. Rasmussen ER, Mey K, Bygum A. Angiotensin-converting enzyme inhibitor-in duced angioedema-a dangerous new epidemic. Acta Derm Venereol. 2014;94: 260-4.

17. Gang C, Lindsell CJ, Moellman J, Sublett W, Hart K, Collins S, et al. Factors associated with hospitalization of patients with angiotensin-converting enzyme inhibitor-induced angioedema. Allergy Asthma Proc. 2013;34:267-73.

18. Banerji A, Clark S, Blanda M, LoVecchio F, Snyder B, Camargo CA. Multicente study of patients with angiotensin-converting enzyme inhibitor-induced angioedema who present to the emergency department. Ann Allergy Asthma Immunol. 2008;100:327-32.

19. Kim SJ, Brooks JC, Sheikh J, Kaplan MS, Goldberg BJ. Angioedema deaths in the United States, 1979-2010. Ann Allergy Asthma Immunol. 2014;113:630-4.

20. Rupnik E, Kariž S, Iglič Č, Zidarn M, Košnik M. Življenje ogrožajoč angioedem po zaviralcu angiotenzinove konvertaze: prikaz dveh primerov [Life-threatening angioedema induced by angiotensin-converting enzyme inhibitor: two case reports]. Zdr Vestn. 2015;84:12. Slovene.

21. Gainer JV, Nadeau JH, Ryder D, Brown NJ. Increased sensitivity to bradykinin among African Americans. J Allergy Clin Immunol. 1996;98:283-7.

22. Mahmoudpour SH, Leusink M, van der Putten L, Terreehorst I, Asselbergs FW, de Boer A, et al. Pharmacogenetics of ACE inhibitor-induced angioedema and cough: a systematic review and meta-analysis. Pharmacogenomics. 2013;14:249-60.

23. Baş M, Greve J, Stelter K, Havel M, Strassen U, Rotter N, et al. A randomized trial of icatibant in ACE-inhibitor-induced angioedema. N Engl J Med. 2015;372:418-25.

24. Strassen U, Bas M, Hoffmann TK, Knopf A, Greve J. Treatment of angiotensin receptor blocker-induced angioedema: a case series. Laryngoscope. 2015;125: 1619-23.

25. Bova M, Guilarte M, Sala-Cunill A, Borrelli P, Rizzelli GM, Zanichelli A. Treatment of ACEl-related angioedema with icatibant: a case series. Intern Emerg Med. 2015;10:345-50.

26. Azofra J, Díaz C, Antépara I, Jaúregui I, Soriano A, Ferrer M. Positive response to omalizumab in patients with acquired idiopathic nonhistaminergic angioedema. Ann Allergy Asthma Immunol. 2015;114:418-9. 